\title{
Identification of genes essential for pellicle formation in Acinetobacter baumannii
}

\author{
Sarah K. Giles ${ }^{1}$, Uwe H. Stroeher ${ }^{1}$, Bart A. Eijkelkamp ${ }^{1,2}$ and Melissa H. Brown ${ }^{1 *}$
}

\begin{abstract}
Background: Acinetobacter baumannii is an opportunistic pathogen, which has the ability to persist in the clinical environment, causing acute and chronic infections. A possible mechanism contributing to survival of $A$. baumannii is its ability to form a biofilm-like structure at the air/liquid interface, known as a pellicle. This study aimed to identify and characterise the molecular mechanisms required for pellicle formation in A. baumannii and to assess a broad range of clinical A. baumannii strains for their ability to form these multicellular structures.

Results: Random transposon mutagenesis was undertaken on a previously identified hyper-motile variant of $A$. baumannii ATCC 17978 designated 17978hm. In total three genes critical for pellicle formation were identified; cpdA, a phosphodiesterase required for degradation of cyclic adenosine monophosphate (CAMP), and A1S_0112 and A1S_0115 which are involved in the production of a secondary metabolite. While motility of the A1S_0112::Tn and A1S_0115::Tn mutant strains was abolished, the cpdA::Tn mutant strain displayed a minor alteration in its motility pattern. Determination of cAMP levels in the cpdA::Tn strain revealed a $\sim 24$-fold increase in cellular CAMP, confirming the role CpdA plays in catabolising this secondary messenger molecule. Interestingly, transcriptional analysis of the $c p d A:: T n$ strain showed significant down-regulation of the operon harboring the A1S_0112 and A1S_0115 genes, revealing a link between these three genes and pellicle formation. Examination of our collection of 54 clinical A. baumannii strains revealed that eight formed a measurable pellicle; all of these strains were motile.

Conclusions: This study shows that pellicle formation is a rare trait in A. baumannii and that a limited number of genes are essential for the expression of this phenotype. Additionally, an association between pellicle formation and motility was identified. The level of the signalling molecule CAMP was found to be controlled, in part, by the cpdA gene product, in addition to playing a critical role in pellicle formation, cellular hydrophobicity and motility. Furthermore, CAMP was identified as a novel regulator of the operon A1S_0112-0118.
\end{abstract}

Keywords: Cyclic AMP, Motility, Virulence, Biofilm, Hydrophobicity

\section{Background}

Acinetobacter baumannii is an opportunistic Gramnegative human pathogen that causes severe nosocomial infections primarily in immune-compromised patients; disease states include pneumonia, meningitis and bacteraemia [1-5]. The bacterium can be found in intensive care units and is frequently isolated from medical devices [6-9]. The capacity to survive in these environments is possibly due to the ability of this organism to survive desiccation and resist a broad spectrum of antibiotics

\footnotetext{
* Correspondence: melissa.brown@flinders.edu.au

'School of Biological Sciences, Flinders University, GPO Box 21005001 Adelaide, SA, Australia

Full list of author information is available at the end of the article
}

and disinfectants. As a result, A. baumannii has entrenched itself in the clinical environment [10-12].

Given the occurrence of $A$. baumannii in intensive care units and its high level of intrinsic and adapted resistance, there is increased pressure to identify novel drug targets. Therefore, understanding the molecular mechanisms contributing to virulence in A. baumannii is essential. Similar to numerous other organisms, $A$. baumannii has the ability to grow a multicellular structure known as a biofilm (reviewed by Longo et al. 2014) [13] of which the pellicle is a specialised form. The pellicle is localised to the interface between air and liquid, and is a structure of connected cells surrounded by a matrix of extracellular polymeric substance $[14,15]$. The 
formation of a pellicle allows aerobic bacteria to have access in a stagnant environment to high levels of oxygen and nutrients [16]. The pellicle can increase bacterial survival under antibiotic pressure as well as contribute to longer than usual persistence in a hostile environment, such as under drying conditions [17-19].

There are numerous molecular mechanisms potentially involved in pellicle formation by $A$. baumannii. One such mechanism is the csuA/BABCDE pilus chaperone-usher assembly system which is responsible for the production of pili and is essential in the formation of a biofilm on solid surfaces [2, 9, 20]. In a study on Bacillus subtilis, 288 regulatory and potential regulatory genes were associated with pellicle formation [21]. Recent analyses of $A$. baumannii bacteria in the pellicle state have revealed alterations in the expression of at least 52 membrane proteins (32 up-regulated and 20 down-regulated) $[22,23]$. These 52 proteins were found to be involved in; iron uptake systems, lipid and carbohydrate transport, cellular metabolism, starvation, in addition to porins and pili.

As bacteria encounter a wide range of environmental conditions, there is a requirement to respond to these changes, such as changing from a planktonic state to living within a biofilm and/or pellicle; this can involve deployment of a number of signalling molecules [24, 25]. Cyclic adenosine monophosphate (cAMP) is a ubiquitous signalling molecule used in conjunction with a variety of regulators for modulating gene expression in both prokaryotes and eukaryotes [26, 27]. In bacteria, it has been found to alter multiple virulence characteristics. For example, in Vibrio cholerae cAMP has been implicated in the regulation of cholera toxin, the toxin co-regulated pilus and other pathogenic factors [28]. In Serratia marcesens the importance of the cAMP receptor protein (CRP complex) in the formation of biofilm has been established [26]. In this case the type I fimbriae-dependant biofilm is tightly regulated and a deletion in the phosphodiesterase gene was found to increase cAMP within the bacteria cell and consequently decrease biofilm formation. Conversely, when increased copies of the phosphodiesterase gene are introduced into the bacterial cell, the bacteria enter into what is described as a "hyper biofilm" state [26]. Similarly in Pseudomonas aeruginosa, cAMP has been identified as a key component in biofilm formation, where increased levels of cAMP can inhibit adherence capabilities [29]. Furthermore, in this organism cAMP functions as a co-factor of the virulence factor regulator Vfr, where the cAMP-Vfr complex regulates type III secretion systems involved in exporting toxins and other compounds [30-32]. This complex also regulates virulence factors such as type IV pili, the las quorum sensing system and exotoxin A [32, 33]. Although a vfr-like gene is present in the $A$. baumannii genome, its role in regulation of virulence factors and interaction with cAMP has not been reported.

The proteomic analyses by Marti et al. (2011) and Nait Chabane et al. (2014) suggested that pellicle formation in A. baumannii is not the result of a single gene or operon [22, 23]. Instead, it is likely that pellicle formation is multifactorial, requiring surface-exposed molecular structures and an adequate level of transcriptional regulation. The aim of this study is to provide insight into the genetic elements that contribute to the ability of $A$. baumannii to migrate to a surface and form a pellicle as well as to assess the prevalence of pellicle formation in a number of clinically-relevant $A$. baumannii strains.

\section{Results and discussion}

\section{Pellicle formation is a rare trait in clinical $A$. baumannii} strains

In this study, we have defined the pellicle as a robust layer of connected cells covering the surface of a liquid. To assess the prevalence of pellicle formation, our collection of clinical A. baumannii strains [34] was screened for this phenotype. Pellicle formation was assessed using glass and polypropylene tubes, as these materials are used for a number of implements within the hospital environment and have different surface properties, which may influence the initial attachment and formation of a pellicle. Preliminary assessment of pellicle biomass was conducted at growth temperatures of $25^{\circ} \mathrm{C}$ and $37{ }^{\circ} \mathrm{C}$ (data not shown), which revealed that pellicle growth predominantly occurred at $25{ }^{\circ} \mathrm{C}$; these results coincide with Marti et al. (2011) [35], as such, all subsequent analyses were performed at $25^{\circ} \mathrm{C}$. Of the 54 clinical strains tested only eight formed a robust pellicle, suggesting that this is not a ubiquitous phenotype (Table 1). These eight strains produced varying amounts of total pellicle biomass when comparing glass and polypropylene strata (Table 1). Pellicle formation was categorised into three groups dependent on the amount of pellicle material measured at $\mathrm{OD}_{600}$ where a; "small pellicle" is considered $>0.19$, "moderate pellicle" is considered $>0.20$ and $<0.50$ and "well-developed pellicle" is $>0.51$. In glass tubes, strains ATCC 17978, 17978hm, WM98c, 04145027 and AYE produced a well-developed pellicle, while, AB0057, 11986752 and 2320495 produced a moderate to small pellicle. Analysis in polypropylene tubes showed that only two strains, $17978 \mathrm{hm}$ and 04145027, produced a strong pellicle, while four strains, ATCC 17978, 11986752, 2320495 and WM98c, produced a moderate to small pellicle. Both AYE and AB0057 formed a pellicle in glass tubes, but failed to form a measurable pellicle in polypropylene tubes. Hence, the ability to form a pellicle was not conserved across glass and polypropylene surfaces. These observed differences could be due to a number of factors related to the specific adherence strategies of each strain, such as the production of 
Table 1 Pellicle formation in glass and polypropylene, cell hydrophobicity, motility status and isolation site

\begin{tabular}{|c|c|c|c|c|c|}
\hline A. baumannii isolate & Glass $\left(\mathrm{OD}_{600}\right)$ & Polypropylene $\left(\mathrm{OD}_{600}\right)$ & Hydrophobicity (\%) & Motility & Isolation site \\
\hline \multicolumn{6}{|c|}{ Pellicle forming A. baumannii strains } \\
\hline ATCC 17978 & $0.65 \pm 0.16$ & $0.44 \pm 0.08$ & $32 \pm 0.25$ & + & Meningitis \\
\hline 17978hm & $1.03 \pm 0.01$ & $0.94 \pm 0.02$ & $42 \pm 0.19$ & + & Meningitis \\
\hline 11986752 & $0.13 \pm 0.01$ & $0.17 \pm 0.04$ & $98 \pm 0.01$ & + & Pus \\
\hline 2320495 & $0.35 \pm 0.08$ & $0.28 \pm 0.06$ & $98 \pm 0.03$ & + & Pus \\
\hline WM98c & $1.01 \pm 0.02$ & $0.37 \pm 0.08$ & $94 \pm 0.10$ & + & Unknown \\
\hline 04145027 & $0.62 \pm 0.00$ & $0.79 \pm 0.04$ & $100 \pm 0.00$ & + & Vaginal \\
\hline AYE & $0.65 \pm 0.11$ & Not detected & $92 \pm 0.07$ & + & Urinary \\
\hline AB0057 & $0.47 \pm 0.06$ & Not detected & 0 & + & Blood \\
\hline \multicolumn{6}{|c|}{ Surface film forming A. baumannii strains } \\
\hline 6772166 & $\mathrm{BD}^{a}$ & $\mathrm{BD}$ & 0 & + & Pus \\
\hline 685775 & $\mathrm{BD}$ & $\mathrm{BD}$ & 0 & + & Sputum \\
\hline PW01c & $\mathrm{BD}$ & $\mathrm{BD}$ & 0 & + & Unknown \\
\hline 6877889 & $\mathrm{BD}$ & $\mathrm{BD}$ & $9 \pm 0.09$ & + & Sputum \\
\hline 6870155 & $\mathrm{BD}$ & $\mathrm{BD}$ & $5 \pm 0.07$ & + & Sputum \\
\hline
\end{tabular}

${ }^{a} \mathrm{BD}=$ below detection level

pili and other surface-exposed macromolecules. A number of strains, 6772166, 6856775, PW01c, 6877889 and 6870155 produced a weak surface film that could not be extracted using our protocol, attempts to do so by other means such as draining the planktonic growth resulted in destruction of this weak surface film. Structures such as pilin-like proteins and exopolysaccharides have been shown to be present in pellicles [23] and it is possible that these structures are expressed at a reduced level in these strains resulting in only a weak surface film. Interestingly, all pellicle forming strains and those that formed a weak surface film have been shown to be motile [34]. This finding highlights the possibility that the molecular mechanisms involved in motility and pellicle formation are linked.

\section{Hydrophobicity across the clinical A. baumannii strains is not directly linked to pellicle formation ability}

In a number of bacterial species, including $A$. baumannii, a positive association between cell surface hydrophobicity, biofilm formation and adherence capabilities has been reported [36-38]. We evaluated our set of clinical A. baumannii strains for cell surface hydrophobicity and identified major differences (Fig. 1). Using the divisions

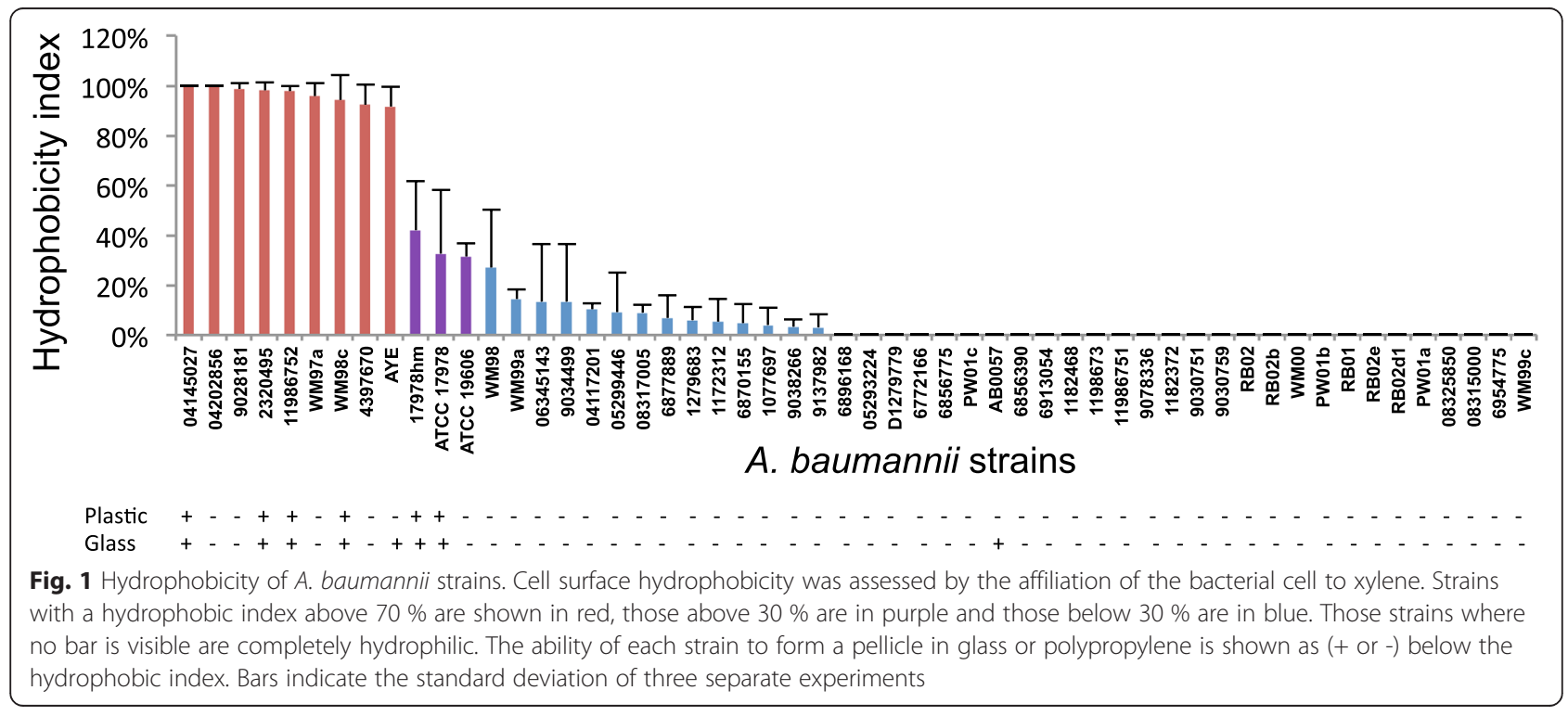


of the hydrophobicity index as established by Pour et al. (2011) [36], 42 of the strains displayed a hydrophilic character, nine were found to have a strong hydrophobic character and three showed an intermediate level of cell surface hydrophobicity. Of the eight strains that formed a pellicle in glass (Table 1), five (11986752, 2320495, WM98c, 04145027 and AYE) were found to have a strong hydrophobicity index of $>70 \%$, two (ATCC 17978 and $17978 \mathrm{hm}$ ) showed an intermediate hydrophobic character and AB0057 was found to be hydrophilic. There are numerous proteins embedded within the outer membrane of Gram-negative bacteria that have a variety of functions including pili for adherence and possibly pellicle formation as well as other physical characteristics. Surface proteins can alter the surface chemistry of a cell and affect the surface hydrophobicity $[39,40]$. The aforementioned results suggest a high level of correlation between the ability to form an extractable pellicle and an increase in cell surface hydrophobicity. The level of hydrophobicity may have an influence on what surface and how strongly bacteria interact due to a variety of proteins on the cell surface [41, 42]. Interestingly, the strains identified as producing a weak surface film all show a hydrophilic nature.

\section{A1S_0112, A1S_0115 and cpdA are essential for pellicle formation in A. baumannii $17978 \mathrm{hm}$}

To further investigate the pellicle phenotype, we used our previously characterised A. baumannii $17978 \mathrm{hm}$ strain (harboring an insertion in hns) [43], which has the ability to produce increased amounts of pellicle material compared to the ATCC 17978 parent strain. This strain was chosen as it allows good discrimination between the pellicle and non-pellicle phenotype allowing ready identification in large scale screening procedures. To identify genes associated with this potential virulence factor a transposon bank of random mutants was constructed in the $17978 \mathrm{hm}$ strain using the plasmid pLOF mini::Tn10:gfp:kan [44]. Approximately 4000 individual transposon insertion mutants were examined in microtitre trays for their ability to form a pellicle. Initial screening identified nine transposon insertion mutants that were incapable of pellicle formation. Subsequent evaluation of these strains in polypropylene and glass tubes confirmed the complete loss of the pellicle phenotype (data not shown). The exact insertion site of the individual transposon insertions were identified by cloning the kanamycin resistance gene associated with the transposon (mini::Tn10:gfp:kan) and subsequent sequencing. Insertions were found to be within three genes: A1S_0249 ( $c p d A)$, a cAMP phosphodiesterase; A1S_0112, acyl-CoA synthetase/adenosine monophosphate (AMP) acid ligase II; and A1S_0115, which is annotated to be involved in amino acid adenylation. The precise insertion site of the transposon is given as the nucleotide position relative to the A. baumannii ATCC 17978 genome sequence (GenBank CP000521) (Additional file 1). Seven transposon insertions were identified to be within the A1S_0115 gene. A single representative of each of the three distinct insertions, designated transposon mutants 1,2 and 5 , was taken for further investigation (Additional file 1).

Transposon mutant 1 was identified as containing an insertion within $c p d A, c p d A::$ Tn. Bacteria finely modulate intracellular cAMP levels through adenylate cyclases (synthesis) and cAMP phosphodiesterases, such as CpdA, which converts cAMP to AMP (degradation) [45]. Therefore, as the insertional inactivation of $c p d A$ led to a loss of pellicle, this insertion identified the requirement for cAMP regulation in this process. To confirm that the observed phenotype can be attributed to disruption of $c p d A$, the $c p d A::$ Tn mutant strain was complemented by cloning a wild-type copy of $\operatorname{cpdA}$ into the empty shuttle vector pWH1266 [46], producing pWH0249. The pWH0249 plasmid was subsequently electroporated into the $c p d A::$ Tn mutant strain generating the strain cpdA:: $\operatorname{Tn}(0249)$ (Table 2). This strain was found to successfully produce a pellicle in contrast to both the cpdA::Tn mutant strain or the $c p d A::$ Tn control strain harboring the empty pWH1266 vector, $c p d A:: \operatorname{Tn}(1266)$ (Table 2; Fig. 2).

Transposon mutant 2 A1S_0112::Tn and transposon mutant 5 A1S_0115::Tn have insertions within the open reading frame (ORFs) A1S_0112 and A1S_0115, which are located in a large operon comprised of seven genes, A1S_0112-0118 (Fig. 3). This operon has previously been associated with cell motility, potentially by production and secretion of a biosurfactant via a type-I secretion system or another mechanism $[47,48]$. A recent report has shown that the genes within this operon are significantly up-regulated in biofilm cells in A. baumannii ATCC 17978 and a site-specific knockout of A1S_0114 abolished biofilm formation [49]. Efforts to complement the A1S_0112::Tn and A1S_0115::Tn transposon mutant strains with copies of the wild-type genes cloned into pWH1266 (Table 2), were unsuccessful possibly due to polar effects of the transposon insertions. In order to ensure that the lack of complementation was not due to a lack of transcription of our complementing genes, we undertook qRT-PCR that revealed adequate transcription occurred for the wild-type A1S_0112 and A1S_0115 genes cloned into the empty pWH1266 vector (Table 3, Additional file 2). As mentioned, pellicle formation was not restored in these mutants, possibly because, these ORFs are part of an operon which must be transcribed as a polycistronic message making complementation of these mutants not possible. This is supported by the work of Clemmer et al. (2011) who previously isolated transposon mutants in this region which abolished motility and 
Table 2 A. baumannii 17978hm mutant derivatives constructed in this study

\begin{tabular}{|c|c|}
\hline Abbreviated name & Description $^{a}$ \\
\hline cpdA::Tn & Tn10:gfp:kan insertion in $c p d A, \operatorname{kan}^{R}$ \\
\hline cpdA::Tn(0249) & Tn10:gfp:kan insertion in cpdA containing pWH0249, kan $^{R}, a m p^{R}$ \\
\hline cpdA:: $\operatorname{Tn}(1266)$ & Tn10:gfp:kan insertion in cpdA containing shuttle vector pWH1266, $\mathrm{kan}^{R}$, amp ${ }^{R}$, tet ${ }^{R}$ \\
\hline A1S_0112::Tn & Tn10:gfp:kan insertion in A1S_0112, kan $^{R}$ \\
\hline A1S_0112::Tn(0112) & Tn10:gfp:kan insertion in A1S_0112 containing pWH0112, $\mathrm{kan}^{R}$, amp ${ }^{R}$ \\
\hline A1S_0112::Tn(1266) & Tn10:gfp:kan insertion in A1S_0112 containing shuttle vector pWH1266, kan $^{R}$, amp $p^{R}$, tet ${ }^{R}$ \\
\hline A1S_0115::Tn & Tn10:gfp:kan insertion in A1S_0115, kan $^{R}$ \\
\hline A1S_0115::Tn(0115) & Tn10:gfp:kan insertion in A1S_0115 containing pWH0115, $\mathrm{kan}^{\mathrm{R}}$, amp ${ }^{R}$ \\
\hline A1S_0115::Tn(1266) & Tn10:gfp:kan insertion in A1S_0115 containing shuttle vector pWH1266, kan $^{R}, a m p^{R}$, tet ${ }^{R}$ \\
\hline
\end{tabular}

${ }^{a} \operatorname{kan}^{\mathrm{R}}$, kanamycin resistance at $50 \mu \mathrm{g} / \mathrm{mL} ; \mathrm{amp}^{\mathrm{R}}$, ampicillin resistance at $100 \mu \mathrm{g} / \mathrm{mL}$; tet ${ }^{\mathrm{R}}$, tetracycline resistance at $12.5 \mu \mathrm{g} / \mathrm{mL}$

due to the nature of this operon were also unable to complement the mutants [47].

\section{Characterisation of pellicle-deficient mutant strains cpdA::Tn, A1S_0112::Tn and A1S_0115::Tn}

The three transposon insertion mutant strains described above were examined for potential growth perturbations in Luria-Bertani (LB) liquid cultures. All three A. baumannii transposon mutant strains showed comparable growth to the parent $17978 \mathrm{hm}$ strain (Additional file 3), indicating that the loss of the

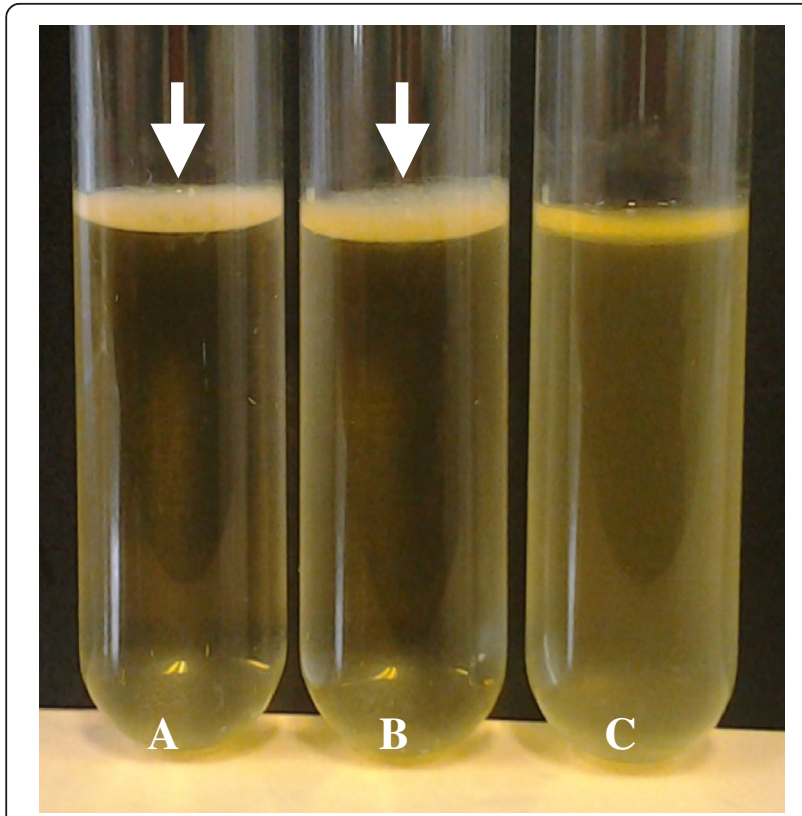

Fig. 2 Pellicle formation by A. baumannii 17978hm parent, cpdA::Tn(0249) and cpdA::Tn(1266) strains. A. baumannii strains were grown in Luria-Bertani broth and analysed after a $72 \mathrm{~h}$ incubation at $25^{\circ} \mathrm{C}$ in the absence of light. Pellicle material was assessed visually. (a) 17978hm parent strain; (b) cpdA::Tn(0249) complemented mutant strain showing developed pellicles at the interface between the liquid and air; and (c) cpdA:: Tn(1266) mutant strain negative for pellicle formation. Arrows identify the pellicle material pellicle is not due to a general growth defect. Since pellicle formation is only one type of biofilm, the ability to form a biofilm at the liquid-surface interface was also examined. The three transposon mutants were assessed for both their planktonic growth potential and their ability to form a biofilm on polypropylene (Fig. 4a and b). All transposon mutants showed an increase in planktonic growth compared to the parent and $c p d A:: \operatorname{Tn}(0249)$ complemented derivative (p-value $<0.001$ ) (Fig. 4a). The transposon insertion mutants were able to form a significantly increased amount of biofilm in polypropylene tubes compared to the parent strain (cpdA::Tn, A1S_0115::Tn and A1S_0112::Tn; p-values of $0.05,0.05$ and 0.01 , respectively) (Fig. $4 \mathrm{~b}$ ), while, the complemented cpdA:: $\operatorname{Tn}(0249)$ mutant strain returned the phenotype to that of the parent (Fig. 4). Carriage of wildtype copies of A1S_0112 and A1S_0115 in their respective Tn mutant derivatives did not result in functional complementation (data not shown).

The three pellicle deficient transposon mutants all displayed a $>80 \%$ reduction in cell surface hydrophobicity compared to the parent strain, to essentially a hydrophilic nature (cpdA::Tn, A1S_0112::Tn and A1S_0115::Tn; p-values of $0.001,0.01$ and 0.01 , respectively) (Fig. 5). This indicates that hydrophobicity is affected when $c p d A$, A1S_0112 or A1S_0115 genes are insertionally inactivated. The presence of the wildtype $c p d A$ gene in the $A$. baumannii $c p d A:: \operatorname{Tn}(0249)$ derivative not only complemented the hydrophobicity character, but increased the hydrophobicity index to $60 \%$ which is above the parent strain (p-value $<0.001$ ) (Fig. 5); this would indicate that cAMP is involved in modulating cell surface hydrophobicity. The increase in hydrophobicity above the level seen with the parent strain is likely due to a copy number effect of the wild-type $c p d A$ determinant residing on the pWH1266 plasmid.

Traditionally, A. baumannii has been considered nonmotile due to its lack of flagella; however, two forms of 


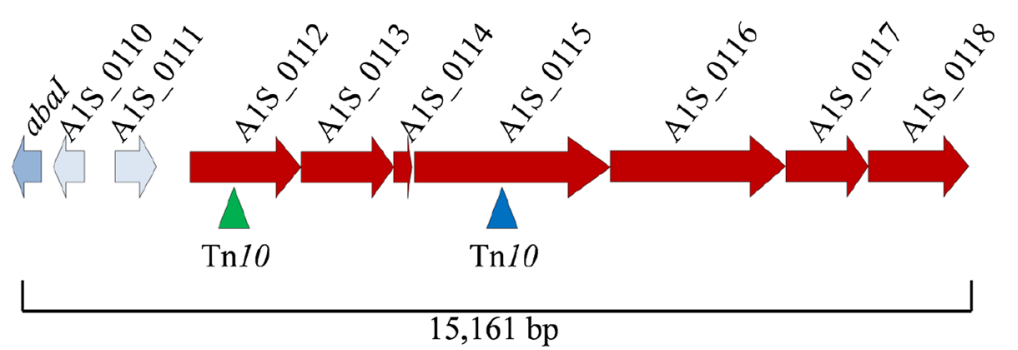

Fig. 3 Operon with transposon insertion sites within A1S_0112 and A1S_0115 identified. The genetic organisation of the A1S_0112-0118 operon is shown with the arrows representing open reading frames and depict the direction of transcription. The location of the transposon (Tn 10 ) insertions in A1S_0112 (green triangle) and A1S_0115 (blue triangle) are shown. Flanking genes illustrate the position of the operon within the chromosome adjacent to the quorum sensing gene abal, A1S_0110 hypothetical protein and A1S_0111 transcriptional regulator; the total size of the region shown is $15,161 \mathrm{bp}$ in length

motility known as swarming and twitching have now been described in this species [34, 50, 51]. While sliding motility in non-flagellated bacteria can occur by surfactant production in other bacteria [48], twitching motility within $A$. baumannii is mediated by the extension and retraction of type IV pili as a form of surface translocation [5]. We have shown previously that A. baumannii strain $17978 \mathrm{hm}$ is motile via swarming on LB medium containing $0.25 \%$ agar [34]. Therefore, we applied these conditions to examine the motility phenotypes of the three pellicle-deficient transposon mutant strains. The A1S_0112::Tn and A1S_0115::Tn mutant strains proved to be non-motile as they only grew at the initial inoculum site on the agar plate (Fig. 6). The A1S_0112::Tn and A1S_0115::Tn mutant strains harboring either a wild-type copy of A1S_0112 or A1S_0115 or an empty vector pWH1266 also gave a negative result (Fig. 6). Our data corroborate the findings by Clemmer et al. (2011) [47], that the A1S_0112-0118 operon is required for motility as insertions within this operon were found to be non-motile (Fig. 6). However, the loss of motility seen in the transposon mutant strains is not universal because

Table 3 Fold change in gene expression of transposon mutant strains compared to the $17978 \mathrm{hm}$ parent strain

\begin{tabular}{|c|c|c|c|}
\hline Strain & A1S_0112* & A1S_0115* & A1S_0118* \\
\hline$c p d A:: \mathrm{Tn}$ & $-2.8 \pm 0.21$ & ND & ND \\
\hline$c p d A:: \operatorname{Tn}(0249)$ & $1.5 \pm 0.44$ & ND & ND \\
\hline cpdA:: $\operatorname{Tn}(1266)$ & $-5.6 \pm 0.032$ & ND & ND \\
\hline A1S_0112::Tn & NA & $-335.46 \pm 1.42$ & $-28.44 \pm 1.33$ \\
\hline A1S_0112::Tn(0112) & $-0.49 \pm 1.39$ & $-669.37 \pm 1.24$ & $-51.63 \pm 1.70$ \\
\hline A1S_0112::Tn(1266) & $-171.25 \pm 1.68$ & $-325.53 \pm 1.22$ & $-85.43 \pm 1.46$ \\
\hline A1S_0115::Tn & $-1.14 \pm 1.59$ & NA & $-83.29 \pm 1.20$ \\
\hline A1S_0115::Tn(0115) & $-4.1 \pm 1.09$ & $-1.16 \pm 1.63$ & $-28.97 \pm 1.54$ \\
\hline A1S_0115::Tn(1266) & $-0.99 \pm 1.32$ & $-347.29 \pm 1.52$ & $-72.50 \pm 1.14$ \\
\hline
\end{tabular}

$\mathrm{NA}=$ not applicable

$\mathrm{ND}=$ not done

* = data from three biological replicates the $c p d A::$ Tn variant remained motile despite presenting a visually different motility pattern compared to the 17978hm parent strain (Fig. 6). The cpdA::Tn and $c p d A:: \operatorname{Tn}(1266)$ strains presented a spoke like motility pattern, whereas the parent strain formed an even surface film of motile cells. The cpdA:: $\operatorname{Tn}(0249)$ mutant strain returned the motility phenotype to that of the parent covering the $0.25 \%$ agar plate with motile bacterial cells (Fig. 6). As such, motility was not substantially affected, however the manner by which the bacterial cells

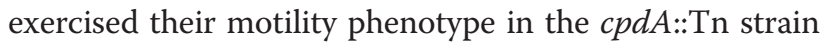
was altered. These results connect the clinical $A$. baumannii strains with the mutant derivatives of the $17978 \mathrm{hm}$ strain, in that, all pellicle forming strains including those that form a weak surface film are motile and when the pellicle is disrupted there is either an alteration in the motile phenotype as seen in the cpdA::Tn mutant or complete abolishment of motility.

Bacterial adherence is a critical virulence factor and aids in host and surface colonisation. The adherence of the $A$. baumannii mutant strains to human lung epithelial cells (A549) was assessed; all three transposon insertion strains had adherence capabilities that were not significantly different to that of the $17978 \mathrm{hm}$ parent strain (data not shown). This suggests that the mechanisms used by $A$. baumannii for pellicle formation are not essential for adherence to A549 human epithelial cells.

\section{The levels of cAMP in the cpdA::Tn mutant strain are significantly increased compared to the $17978 \mathrm{hm}$ parent strain}

The maintenance of intracellular cAMP levels is largely a result of controlling $c p d A$ expression [52]. Therefore, if $c p d A$ is inactivated, cAMP levels are expected to increase in the bacterial cell. Quantification of cAMP levels was achieved using a cyclic nucleotide XP enzymatic immunoassay kit. The $c p d A::$ Tn mutant strain was found to have a level of cAMP approximately 24-fold greater than in the $17978 \mathrm{hm}$ parent strain $(0.5 \mathrm{nM}$ and $12 \mathrm{nM}$, 


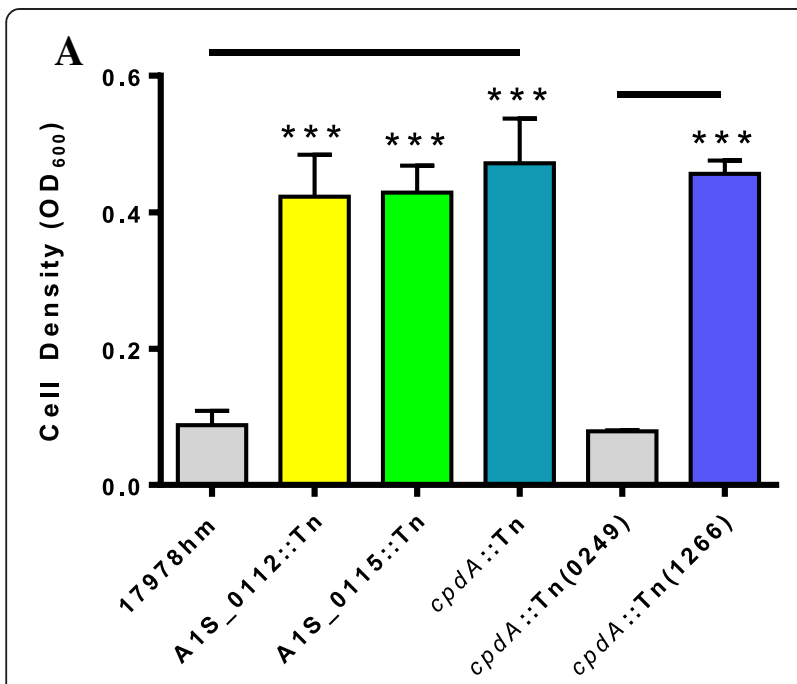

\section{B}

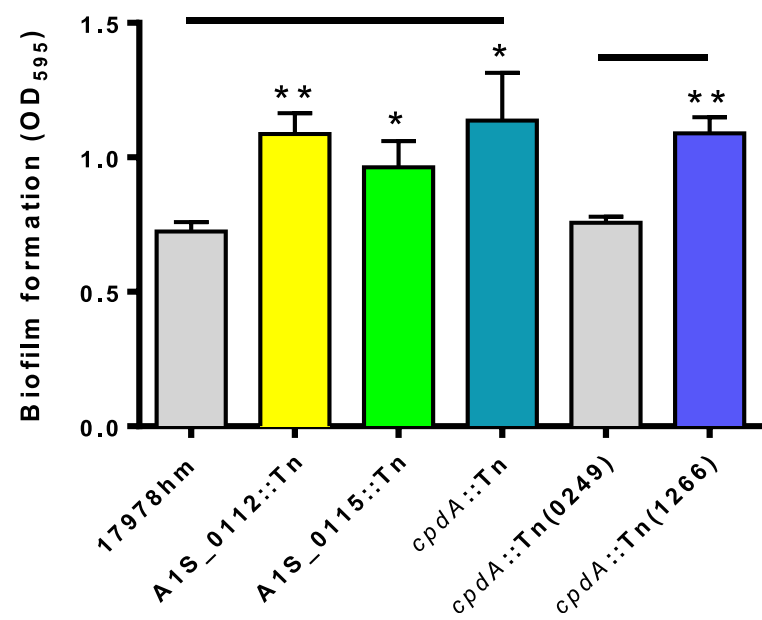

Fig. 4 Planktonic growth and biofilm formation in polypropylene tubes of the transposon mutants and $17978 \mathrm{hm}$ parent strain. Cells were cultured in Luria Bertani media without shaking at $37{ }^{\circ} \mathrm{C}$ in polypropylene tubes for 72 h. (a) Planktonic growth was assessed by removal of $1 \mathrm{~mL}$ of media and the optical density measured at $\mathrm{OD}_{600}$. All three transposon insertion mutant strains showed a dramatic increase of planktonic growth; 4-fold greater than the $17978 \mathrm{hm}$ parent strain. Complementation of the $c d p A$ mutation in the $c p d A:: \operatorname{Tn}(0249)$ strain returned the phenotype to wild-type levels. (b) The level of biofilm produced was assessed by crystal violet staining. Transposon insertion mutant strains had an increased biomass of the surface/liquid biofilm by approximalty $30 \%$ compared to that of the $17978 \mathrm{hm}$ parent. The cpdA::Tn(0249) mutant strain that contains a wild-type copy of the gene, restored the biofilm phenotype to that of the parent. Bars indicate the standard deviation of three separate experiments. Asterisks indicate significant difference: one denotes a $p$-value $<0.05$, two a $p$-value $<0.01$ and three a $p$-value $<0.001$, as determined by a student $t$-test

respectively) (p-value $<0.001$ ) (Fig. 7). This confirmed that $c p d A$ is involved in cAMP homeostasis within the cell and that the disruption of this gene dramatically affects the accumulation of this secondary signalling molecule. Examination of cAMP levels in strains $c p d A:: \operatorname{Tn}(0249)$ and

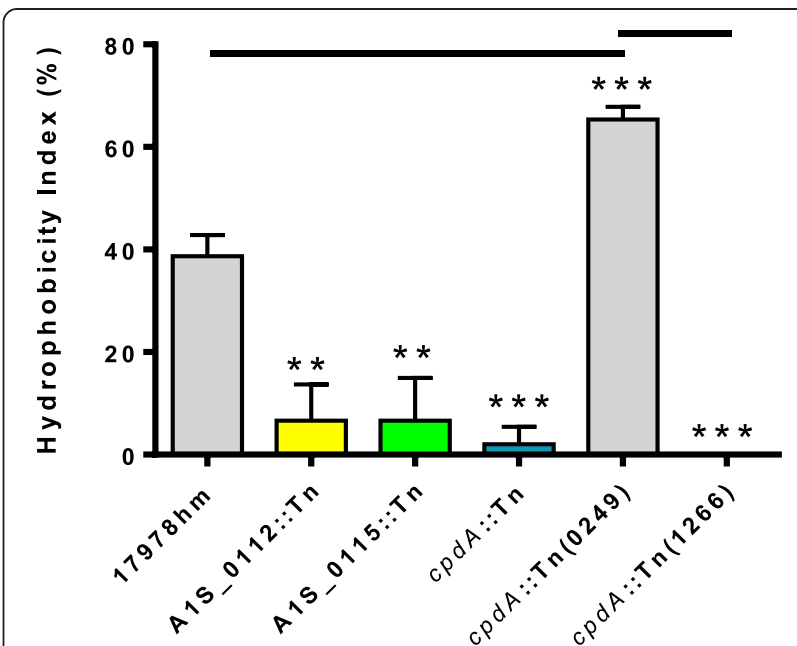

Fig. 5 Hydrophobicity index for A1S_0112::Tn, A1S_0115::Tn and cpdA::Tn transposon insertion mutants. Hydrophobicity results were obtained by assessing the bacterial cell affiliation to xylene. The optical density of the cell suspension before $\left(\mathrm{OD}_{\text {inital }}\right)$ and after $\left(O D_{\text {final }}\right)$ the addition of xylene was measured at $600 \mathrm{~nm}$. All the transposon insertion mutant strains have reduced cell hydrophobicity compared to the parental strain. The cpdA:: $\operatorname{Tn}(0249)$ mutant strain with a wild-type copy of $c p d A$ has a hydrophobicity greater than the $17978 \mathrm{hm}$ parent strain. Bars indicate the standard deviation of three separate experiments. Asterisks indicate significant difference: two denotes a p-value $<0.01$ and three a p-value $<0.001$, as determined by a student $t$-test

cpdA:: $\operatorname{Tn}(1266)$ showed that the phenotype could be specifically attributed to the inactivation of $c p d A$ (Fig. 7).

\section{Transcriptional profiling of the $c p d A:: T n$ mutant strain under motility conditions}

To assess the association between pellicle formation and motility qRT-PCR was undertaken on the $A$. baumannii $17978 \mathrm{hm}$ parent and the $c p d A::$ Tn transposon mutant strain grown under previously identified motility conditions, i.e. on semi-solid LB agar [43]. Analysis of the operon A1S_0112-0118 (Fig. 3) was undertaken by quantifying the transcription of the A1S_0112 gene, which is the first gene in the operon. In the $c p d A::$ Tn strain, the transcription level of A1S_0112 was 2.8-fold down-regulated compared to the $17978 \mathrm{hm}$ parent (Table 3). This indicated that CpdA via cAMP plays a role, either directly or indirectly, in regulation of the A1S_0112-0118 operon. This potential regulatory role of $\mathrm{CpdA}$ and CAMP on the A1S_0112-0118 operon could explain the altered motility phenotype seen in the $c p d A::$ Tn mutant strain, possibly due to alteration in the production of a biosurfactant or through another unknown mechanism(s).

The A1S_0112-0118 operon described above has previously been shown to be activated by quorum-sensing signals in the form of homoserine lactone (abaI, A1S_0109) [47]. Furthermore, Saroj and Rather (2013) have shown that down-regulation of abaI leads to a 

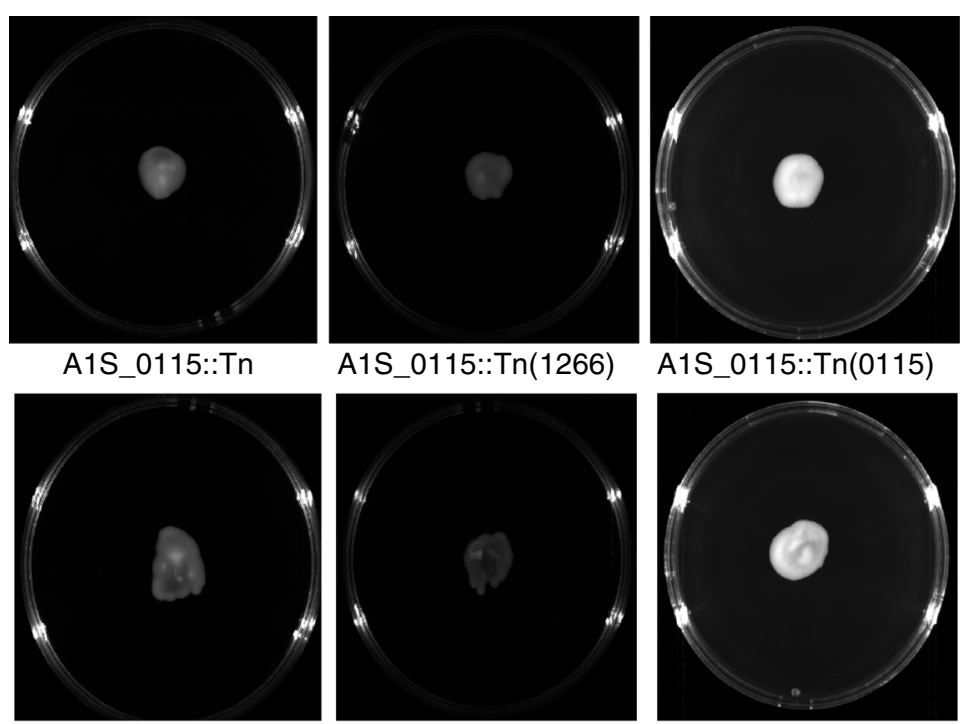

A1S_0115::Tn(0115)
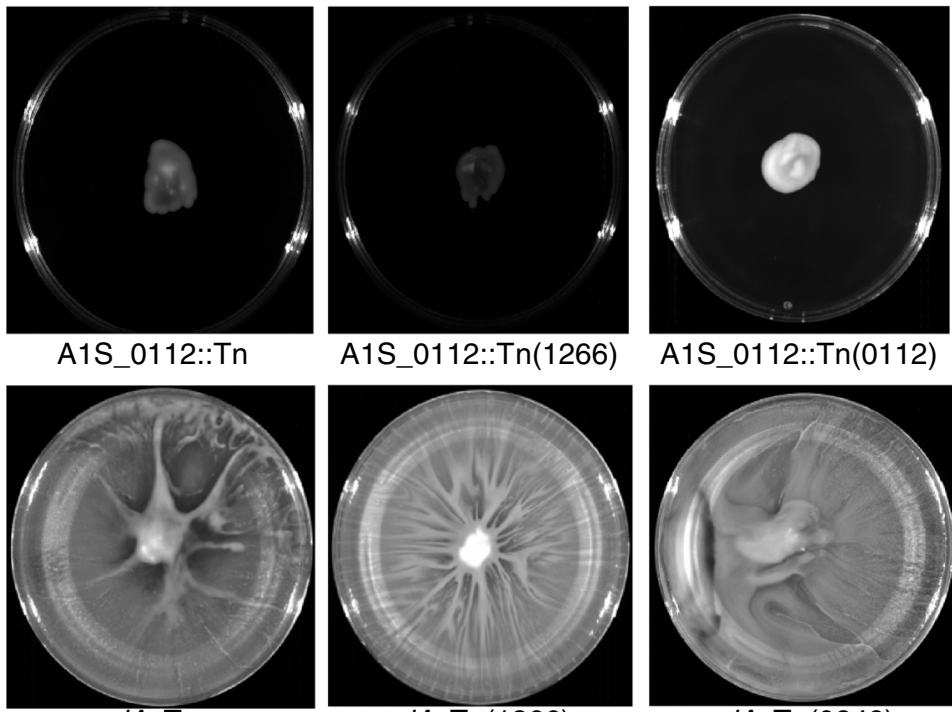

cpdA::Tn
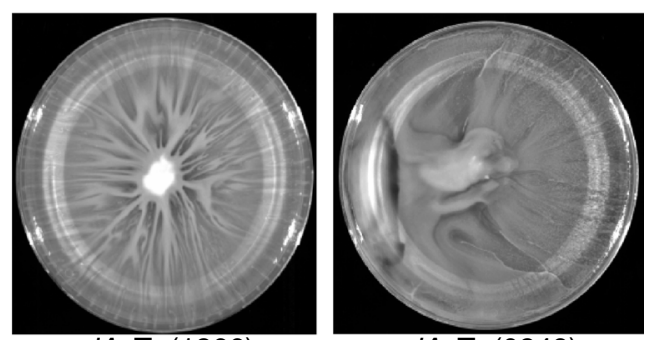

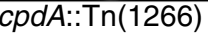

$c p d A:: \operatorname{Tn}(0249)$

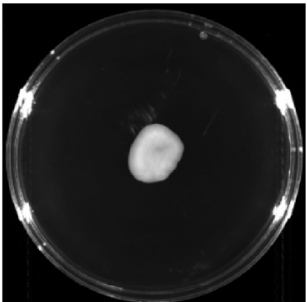

ATCC 17978

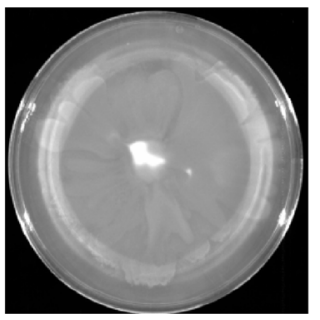

17978hm

Fig. 6 Motility of A. baumannii ATCC 17978, 17978hm, and transposon insertion mutants cpdA::Tn, A1S_0112::Tn and A1S_0115::Th. Overnight grown bacterial cells were used to inoculate Luria-Bertani media containing $0.25 \%$ agar; plates were grown overnight at $37^{\circ} \mathrm{C}$. The A1S_0115::Tn, A1S_0115(0115) and A1S_0115(1266) transposon mutant strains and the A1S_0112::Tn, A1S_0112::Tn(0112) and A1S_0112::Tn(1266) transposon mutant strains only show growth at the initial inoculum site at the centre of the plate giving a non-motile phenotype. However, the cpdA::Tn, cpdA::Tn(0249) and cpdA::Tn(1266) transposon mutant strains retained motility. The complemented strain cpdA::Tn(0249) displayed a motility pattern almost identical to the 17978hm parent, whereas cpdA:Tn and cpdA::Tn(1266) displayed a "spoke-like" motility pattern. ATCC 17978 is included as a control displaying a non-motile phenotype

reduction in motility in $A$. nosocomialis strain $\mathrm{M} 2$ $[53,54]$. Therefore, to examine whether the insertional inactivation of $c p d A$ in the $c p d A::$ Tn mutant had a regulatory effect on the quorum sensing gene abaI when grown on motility media, we assessed the levels of transcription of abaI using qRT-PCR. The results revealed that, despite the altered motility phenotype of the derivative, abaI is expressed at a level comparable to the parent strain $(\sim 1.2$-fold increase). This suggests that the A1S_0112-0118 operon is regulated independently by two different factors; quorum-sensing (AbaI) and cAMP.
Levels of cAMP act as one of the major signalling molecules within the cell and have been show to regulate numerous genes in other bacterial species such as $P$. aeruginosa and Escherichia coli, possibly through activation of Vfr [33]. In $P$. aeruginosa, $v f r$ is auto-regulated and upon inactivation of $c p d A$, vfr expression increases by 12 -fold $[33,45]$. We investigated this possibility in our cpdA::Tn mutant strain by examining the transcript of the putative $v f r$ gene (A1S_1182). The qRT-PCR results showed a 1.7-fold decrease in $v$ fr expression in the cpdA::Tn mutant strain compared to the $17978 \mathrm{hm}$ 


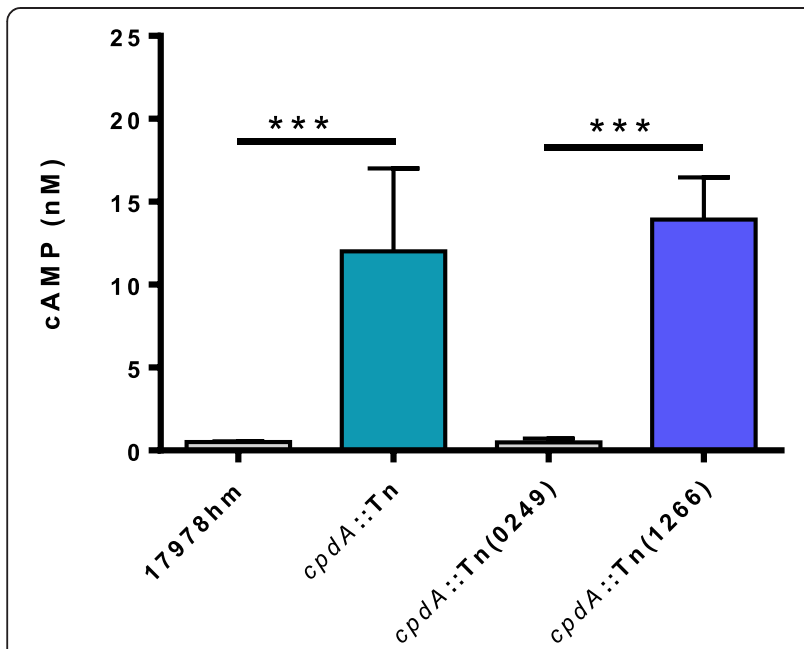

Fig. 7 Determination of intracellular CAMP levels. Bacterial cells were grown to an $\mathrm{OD}_{600}$ of 0.7 , disrupted and CAMP levels determined using the Cyclic Nucleotide XP Enzymatic Immunoassay kit. The amount of CAMP is given in $\mathrm{nM}$ representing a sample corresponding to $1 \mathrm{mg}$ of total cellular protein. Bars indicate the standard deviation of three separate experiments. The cpdA::Tn transposon mutant has $12 \mathrm{mM}$ of CAMP compared to the parent $17978 \mathrm{hm}$ strain which has $0.5 \mathrm{mM}$ of cAMP within the cell. The $c p d A:: \operatorname{Tn}(0249)$ mutant strain returned the CAMP levels to that of the $17978 \mathrm{hm}$ parent strain. The cpdA::Tn mutant strain harboring the empty vector pWH1266 had no effect on the cAMP levels. Asterisks indicate significant difference ( $p$-value <0.001) as determined by one-way Anova

parental strain, that, by a student $t$-test, was determined to be statistically insignificant. Thus, although a 1.7 -fold reduction in $v f r$ transcription was observed it is not known whether cAMP and Vfr work in concert in $A$. baumannii.

\section{Whole transcriptome analysis of the CpdA mutant} compared to the $17978 \mathrm{hm} \mathrm{A}$. baumannii parent strain

Alterations in the level of intracellular cAMP are known to affect a plethora of phenotypes, including alterations in metabolic processes, biofilm formation and cell surface hydrophobicity [52]. Therefore, RNA sequencing was used to investigate the transcriptome of the $\operatorname{cpdA::Tn~mutant}$ grown in Mueller Hinton broth, in order to assess the impact high levels of cAMP have within the bacterial cell. Transcriptome sequencing revealed that many genes were differentially expressed in the $c p d A::$ Tn mutant compared to the parent. Of the approximately 3400 annotated genes in ATCC 17978, 184 genes were more than 2-fold upregulated and 494 genes were more than 2 -fold downregulated (Fig. 8). The most highly up-regulated gene is identified as an alcohol dehydrogenase (A1S_1274) which showed a 34-fold increase in expression, whereas the greatest down-regulated gene is a putative transcriptional regulator (A1S_1256) showing a 29-fold decrease of expression (Fig. 8).
A number of the genes down-regulated in the cpdA::Tn mutant include genes encoding phage-related proteins (A1S_2021-2033), putative acyl carrier proteins, ferric enterobactin receptors, porins, signal peptides, membrane proteins and numerous hypothetical ORFs with no known function (Fig. 8). Variations in the expression of multiple potential transcriptional regulators were also observed; this may be due to the significant alterations that CAMP levels have on the general metabolism of the cell. Genes of particular interest in this study that are down-regulated include the CsuA/ BABCDE system (A1S_2213-2218) (9 to 20-fold), the hms operon which consists of three genes designated A1S_2160 to A1S_2162) (10 to12-fold), and a chaperone usher system (A1S_1507-1510) (2-fold). Proteins encoded by the $c s u$ cluster and chaperone usher system have been identified in pellicle and biofilm formations $[2,20,22,23,34,55,56]$. Interestingly, a single polynucleotide polymorphism leading to truncation of the $\operatorname{csu} B$ gene potentially inactivating this operon has been identified within ATCC 17978 [2, 22, 56]. Within the hms operon two proteins (A1S_2160 and A1S_2161) share an average of $44 \%$ identity with the PgaBC proteins (A1S_0938-0939), the third protein within Hms (A1S_2162) has been designated as a biofilm synthesis protein and shares no homology to the Pga proteins in A. baumannii ATCC 17978. The Pga system has previously been identified as being important in biofilm formation [57]. Interestingly, a recent paper by Nait Chabane et al. (2014) [23] found that CsuA/BABCDE, PgaABC proteins and the chaperone usher system described above, are over represented within $A$. baumannii strains displaying a pellicle phenotype. This suggests that the Hms and chaperone usher pilus proteins could be key components in the formation of the pellicle matrix.

Numerous genes which are up-regulated encode proteins involved in oxidative phosphorylation (Fig. 8). In particular, these include those encoding ubiquinol oxidase subunit I and II (A1S_1434 and A1S_1433) which are 5.7- fold and 4.9-fold up-regulated, respectively. Other genes involved in oxidative phosphorylation include the NADH dehydrogenase complex (A1S_07620764) and the ATP synthetase complex (A1S_01480156). One of the most highly up-regulated genes (A1S_1387) is an oxidoreductase (18-fold); this class of enzymes is often involved in the FAD to $\mathrm{FADH}_{2}$ conversion, where $\mathrm{FADH}_{2}$ plays a major role in oxidative phosphorylation. Therefore, many of the up-regulated genes are involved in the energy, and by extension, the metabolic status of the cell which is not surprising given the central role cAMP plays in cell metabolism.

Other genes of interest which were significantly upregulated are those involved in $50 \mathrm{~S}$ and $30 \mathrm{~S}$ ribosome assembly. The potential role of these up-regulated 


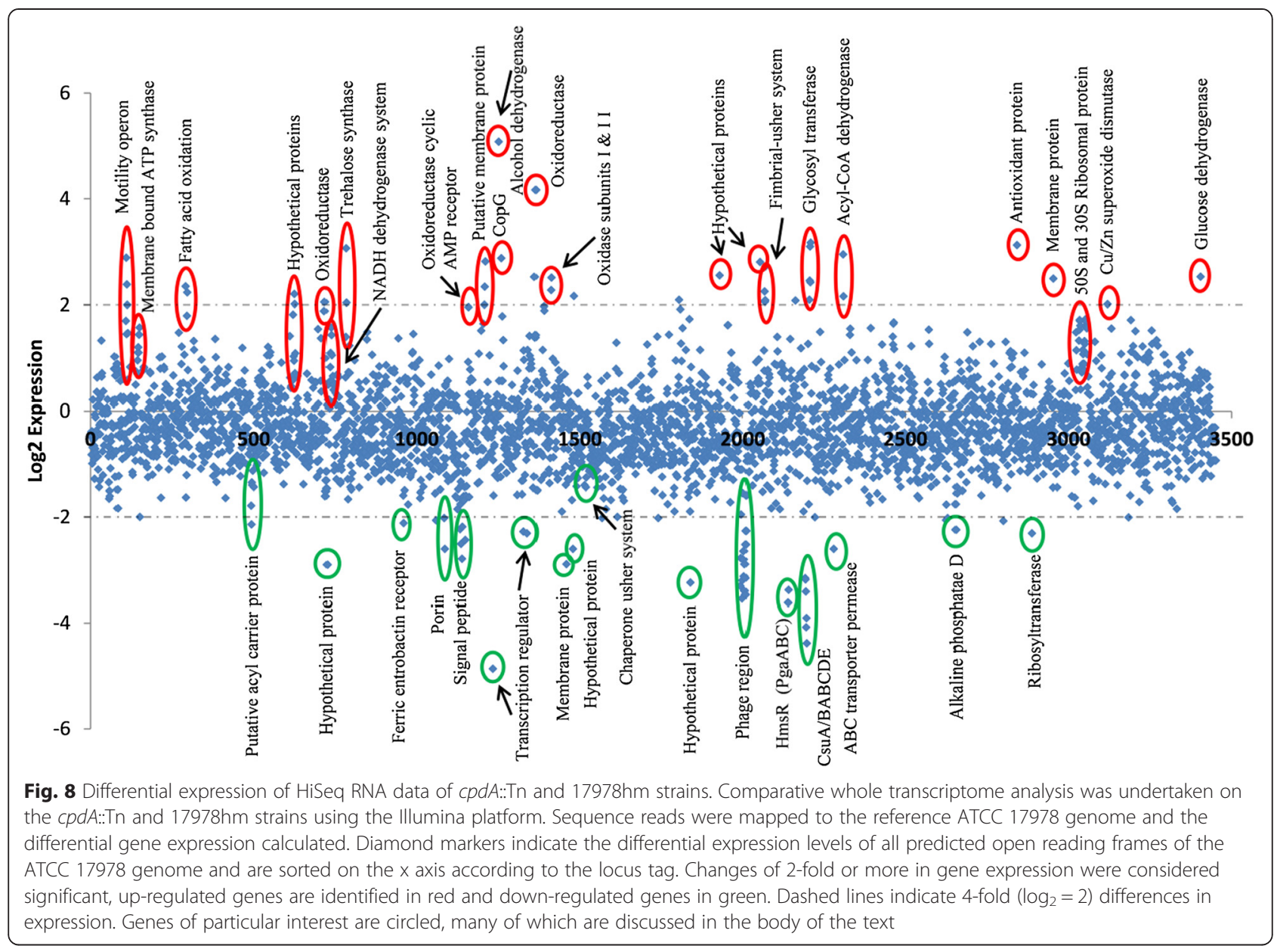

ribosomal proteins maybe in the assembly of $100 \mathrm{~S}$ ribosomes, as these are required for cells to survive long term nutrient stress in situations where glucose is low and cAMP is high [58]. Other up-regulated genes including those involved in fatty acid oxidation, trehalose synthase, membrane proteins, dehydrogenase proteins and a number of proteins which are annotated as hypothetical ORFs.

A small operon consisting of 4 genes (A1S_2088-2091) was identified as having 4-fold increase in expression. Proteins encoded by this region have recently been found in extracted pellicle material [23]. Since, $c p d A .:$ Tn is not capable of pellicle production it would seem unlikely that the A1S_2088-2091 operon is involved in this phenotype, however, $c p d A::$ Tn does show an increase in biofilm formation compared to the parent strain and as such this operon may contribute to liquid/surface biofilm production.

The previously described motility operon A1S_01120118 [47] is up-regulated approximately 3.8 -fold in the cpdA::Tn mutant transcriptome, which is in contrast to RT-PCR data (Table 3). These RT-PCR studies were conducted on motility agar to look at the influence of motility on the change in transcription of this operon. On motility agar both cAMP and quorum sensing may play a role in the control of this operon, however in liquid culture grown to mid-log phase used for the RNAsequence analysis, cAMP appears to be solely responsible for the regulation of A1S_0112-0118.

\section{Conclusions}

This report has shown that pellicle formation is a phenotypic trait seen in a limited number of $A$. baumannii strains. For the first time, the secondary signalling molecule cAMP has been shown to play a critical role in pellicle formation as well as motility in $\mathrm{A}$. baumannii. Additionally, this study has shown that insertions in CpdA, A1S_0112 and A1S_0115 completely abolish pellicle formation. Furthermore, transcriptional analyses identified that cAMP effects the expression of the A1S_0112-0118 operon essential for motility, thereby altering the migration pattern seen in the $c p d A$ ::Tn mutant strain grown on semi-sold agar; insertions in the above operon in A1S_0112 and A1S_0115 resulted in a non-motile phenotype. We thus speculate, that pellicle and motility phenotypes of $A$. baumannii are linked via the expression of cAMP and the 
A1S_0112-0118 operon. Increased cell surface hydrophobicity was identified as an indicator of pellicle formation ability in the clinical strains tested herein. Whole transciptome analysis has identified an abundance of ORFs affected by the increase in cAMP within the $c p d A::$ Tn mutant. A number of these correlate with genes previously known to be involved in pellicle formation including the hms locus and a chaperone usher system as well as the A1S_0112-0118 region identified in this study. Considering the importance of pellicle formation in the persistence and transmission of numerous bacterial species, this study has contributed to our understanding of the regulatory mechanisms behind these significant virulence traits in A. baumannii.

\section{Methods}

\section{Bacterial strains}

The 54 clinical A. baumannii bacterial strains used in this study and the hyper-motile derivative of $A$. baumannii ATCC 17978 designated $17978 \mathrm{hm}$ have been described previously $[34,59]$. All A. baumannii strains were cultured on LB media containing $1 \%$ agar overnight at $37{ }^{\circ} \mathrm{C}$, and single colonies transferred to $\mathrm{LB}$ broth for subsequent use in assays, unless otherwise stated. For maintenance, conjugation, cloning and replicating plasmids E. coli DH5 $\alpha$, SM10 or JM109 cells were used [60-62].

\section{Assessment of pellicle formation}

The pellicle formation assay was adapted from previously described protocol [35]. In brief, overnight bacterial cultures were diluted 1:100 in $5 \mathrm{~mL}$ of LB broth and grown stagnant in polypropylene or glass tubes for $72 \mathrm{~h}$ at $25{ }^{\circ} \mathrm{C}$ without shaking in the dark [63, 64]. Quantitative measurement of the pellicle material was assessed by the addition of $1 \mathrm{~mL}$ of ethanol into the tube underneath the pellicle material. The floating pellicle was then removed and resuspended in phosphate buffered saline (PBS) and the $\mathrm{OD}_{600}$ measured using a spectrophotometer (Beckman DU 640). Quantitative data were collected from at least three experiments on three different days.

\section{Motility assays}

Motility was assessed by migration on semi-solid surfaces using media containing $0.25 \%$ agar as described previously [34]. Briefly, an overnight colony was collected using a sterile loop and used to inoculate the centre of LB medium containing $0.25 \%$ agar. The plate was then incubated overnight at $37^{\circ} \mathrm{C}$. Strains were considered motile if any movement of growth from the original inoculation site was observed.

\section{Eukaryotic cell adherence assays}

A. baumannii cell adherence to A549 (human type 2 pneumocytes) was investigated as previously described [34]. In brief, cell lines were grown in Dulbecco's Modified Eagle medium (Invitrogen, Australia) supplemented with $10 \%$ foetal bovine serum (Bovogen, Australia). Washed A549 monolayers in 24-well tissue culture plates were infected with bacterial inoculums containing $\sim 1 \times 10^{7}$ colony forming units. After incubation at $37^{\circ} \mathrm{C}$ for $4 \mathrm{~h}$ the culture medium was removed and the monolayers washed with PBS. The cell monolayers were detached from the plate using a treatment of $100 \mu \mathrm{L}$ of $0.25 \%$ trypsin in PBS. Eukaryotic cells were subsequently lysed by the addition of $400 \mu \mathrm{L} 0.025 \%$ Triton X-100 and serial 10-fold dilutions were spread plated on LB agar to determine the number of colony forming units of adherent bacteria per well. The collated data for the adherence assay were obtained from at least three independent experiments and represent the data points from each experiment in quadruplicate wells.

\section{Cell surface hydrophobicity tests}

Cell surface hydrophobicity was examined as described previously [65]. In brief, overnight cultures were diluted in LB broth and incubated at $37^{\circ} \mathrm{C}$ for $2 \mathrm{~h}$. Potassium urea magnesium buffer was used to wash the cells twice, before incubation at $30^{\circ} \mathrm{C}$ for $20 \mathrm{~min}$. The cell suspension was adjusted to $\mathrm{OD}_{600} \sim 0.25$ in the same buffer in glass vials before the addition of xylene $(3 \mathrm{~mL})$. The sample was vortexed for $20 \mathrm{sec}$ and the aqueous phase transferred to a $1.5 \mathrm{~mL}$ tube. The $\mathrm{OD}_{600}$ of the cell suspension was determined before $\left(\mathrm{OD}_{\text {initial }}\right)$ and after $\left(\mathrm{OD}_{\text {final }}\right)$ the addition of xylene. The hydrophobicity index, expressed as a percentage, is calculated as $\left(\mathrm{OD}_{\text {inital }}-\mathrm{OD}_{\text {final }} / \mathrm{OD}_{\text {initial }}\right)^{* 1} 100$. Quantitative data were collected from at least three experiments from three different days.

\section{Transposon mutagenesis}

Transposon mutagenesis was undertaken using a modified mini Tn10 transposon (mini::Tn10:gfp:kan) carried on the plasmid pLof [66]. The pLof mini::Tn10:gfp:kan plasmid was transformed into the donor E. coli SM10 strain and mated with the A. baumannii $17978 \mathrm{hm}$ recipient at a 1:10 ratio for $4 \mathrm{~h}$ at $37^{\circ} \mathrm{C}$ on LB agar exconjugates were resuspended in $5 \mathrm{~mL}$ of $\mathrm{LB}$ broth and plated onto selective media containing $50 \mu \mathrm{g} / \mathrm{mL}$ kanamycin and $25 \mu \mathrm{g} / \mathrm{mL}$ chloramphenicol to select for transposition events and counter-select against the $E$. coli SM10 donor strain. Approximately, 4000 exconjugates were individually picked using sterile toothpicks to inoculate $200 \mu \mathrm{L}$ of LB broth in 96 well microtitre plates. The cells were grown at $25{ }^{\circ} \mathrm{C}$ in the dark for $72 \mathrm{~h}$ and assessed visually for pellicle loss. 


\section{Identification of mini::Tn10:gfp:kan insertion in the chromosome}

Chromosomal DNA isolated from A. baumannii 17978hm containing the mini::Tn10:gfp:kan was digested with restriction endonucleases $\mathrm{XbaI}$ and SacII for $4 \mathrm{~h}$ at $37{ }^{\circ} \mathrm{C}$. Digested products were cloned into pBluescript SK II (Agilent technologies, CA, USA) and clones were confirmed by sequencing (Australian Genome Research Facility, Adelaide, South Australia). The insertion site of the transposons in the chromosome was determined by Sanger sequencing using an oligonucleotide designed to read out of the end of the transposon (see Additional file 2).

\section{Complementation of transposon insertions}

For genetic complementation of the non-pellicle forming A. baumannii mutants, the genes corresponding to A1S_0112, A1S_0115 and cpdA were PCR amplified, cloned into the shuttle vector pWH1266, transformed into $\mathrm{DH} 5 \alpha$ E. coli cells and sequenced. Plasmids were extracted and subsequently transformed via electroporation using a MicroPulser (Bio-Rad, CA, USA) at $2.5 \mathrm{kV}$, $200 \mathrm{ohms}$ and 25 microfarads into their respective $A$. baumannii transposon insertion strains [46]. PCR was achieved with VELOCITY ${ }^{\mathrm{mM}}$ DNA polymerase (Bioline, Vic, Australia) and the oligonucleotides (Additional file 2) using the following PCR protocols. For amplification of $c p d A$, cycling conditions were $2 \mathrm{~min}$ at $94{ }^{\circ} \mathrm{C}, 30 \mathrm{cy}$ cles of $45 \mathrm{sec}$ at $94{ }^{\circ} \mathrm{C}, 45 \mathrm{sec}$ at $55^{\circ} \mathrm{C}$, and $90 \mathrm{sec}$ at $72{ }^{\circ} \mathrm{C}$, followed by a final extension of $4 \mathrm{~min}$ at $72{ }^{\circ} \mathrm{C}$. Amplification of A1S_0112 used the same conditions with the exception of the annealing temperature which was increased to $60{ }^{\circ} \mathrm{C}$. For amplification of A1S_0115, the cycling conditions were $2 \mathrm{~min}$ at $94{ }^{\circ} \mathrm{C}, 30$ cycles of $90 \mathrm{sec}$ at $94{ }^{\circ} \mathrm{C}, 90 \mathrm{sec}$ at $60{ }^{\circ} \mathrm{C}, 4 \mathrm{~min}$ at $72{ }^{\circ} \mathrm{C}$ and a final extension of $6 \mathrm{~min}$ at $72{ }^{\circ} \mathrm{C}$.

\section{Measurement of intracellular cAMP levels}

Assessment of cAMP levels within A. baumannii strains cpdA::Tn, cpdA::Tn(0249), cpdA::Tn(1266) and 17978hm was performed with cells were grown to an $\mathrm{OD}_{600}$ of 0.7. Cells were pelleted by centrifugation at $4500 \mathrm{~g}$ for $15 \mathrm{~min}$, resuspended in PBS and disrupted at 30,000 lb per square inch using the One Shot Head from the TS series bench top disruptor (Constant Systems, United Kingdom). The resulting cellular material in the cell lysis solution was clarified by centrifugation at $4500 \mathrm{~g}$ for 30 min and the supernatant removed and stored at $-80{ }^{\circ} \mathrm{C}$ until required. The concentration of cAMP was measured using the Cyclic Nucleotide XP Enzymatic Immunoassay kit (Cell Signalling Technology, MA, USA) according to the manufacturer's instructions. In brief, 50 $\mu \mathrm{L}$ of horseradish peroxidase-linked cAMP solution and $50 \mu \mathrm{L}$ of sample were added to the supplied 96-well tray, which was then covered and incubated at room temperature for $3 \mathrm{~h}$ on a horizontal orbital plate shaker. The contents of the plate were discarded and the plate was washed 4 times with $200 \mu \mathrm{L} /$ well of wash buffer. Next, $100 \mu \mathrm{L}$ of 3,3',5,5'-tetramethylbenzidinesubstrate solution was added and incubated for $30 \mathrm{~min}$ at room temperature, after which $100 \mu \mathrm{L}$ of stop solution was added and the absorbance measured at $450 \mathrm{~nm}$. Using the inverse for the standards derived from a standard curve and adjusted for the amount of total protein added, the amount of cAMP was calculated. Total protein concentrations were quantified using the Lowry protein assay (Bio-Rad, CA, USA) following the manufacturer's instructions.

\section{Isolation of total cellular RNA}

To measure transcriptional levels for either RT-PCR or in Hiseq RNA transcriptome analysis conducted by SA Pathology (Central Adelaide local Health Network via an Illumina platform), cells were isolated and RNA extracted as below. Bacterial cells were harvested from either semi-solid media $(0.25 \%$ LB agar) for RT-PCR using pre-chilled PBS or harvested from Mueller Hinton broth at $\mathrm{OD}_{600}$ of 0.6 for Hiseq. Bacterial cells were pelleted by centrifugation at $4500 \mathrm{~g}$ for $15 \mathrm{~min}$ and lysed in $1 \mathrm{~mL}$ TRIzol reagent (Life Technologies, Australia) and $200 \mu \mathrm{L}$ of chloroform. Following phase separation, the aqueous layer was collected and RNA isolated using the Isolate RNA Mini Kit (Bioline, NSW, Australia) following the manufacturer's recommendations. Samples for RT-PCR were subsequently treated with DNaseI (Promega, WI, USA) for $30 \mathrm{~min}$ at $37{ }^{\circ} \mathrm{C}$ and $1 \mu \mathrm{L}$ of stop solution was added before a final incubation for $10 \mathrm{~min}$ at $65{ }^{\circ} \mathrm{C}$. Triplicate samples were pooled and sent to SA Pathology for Ribosomal RNA reduction using Epicentre Ribo-Zero kit and RNA library bar-coding was undertaken on RNA for HiSeq. Samples were run on the Illumina HiSeq platform (1X50 base pair single reads). These data are accessible through GEO Series accession number GSE64935 (http://www.ncbi.nlm.nih.gov/geo/ query/acc.cgi?acc= GSE64935).

\section{Bioinformatic analysis}

The quality of the cDNA reads obtained from the HiSeq was checked using 'Fastqc' (http://www.bioinformatics.babraham.ac.uk/projects/fastqc/). Reads were subsequently mapped to the reference genome using 'bowtie' aligner (http://bowtie-bio.sourceforge.net/index.shtml). For the reads obtained, approximately $95 \%$ were mapped to the ATCC 17978 genome of which $78 \%$ mapped to the coding regions. In order to determine changes in gene expression the number of reads obtained for each ORF was normalised using reads per kilobase of transcript per million reads mapped. 


\section{Quantitative reverse transcription PCR}

M-MLV reverse-transcriptase (Promega) and random hexamers (GeneWorks, SA, Australia) were used to synthesise complementary deoxyribonucleic acid (cDNA) following the manufacturer's recommendations. qRTPCR was performed on three biological replicates using DyNAmo SYBR green qRT-PCR kits (ThermoScientific, Vic, Australia) in conjunction with a Rotor-Gene RG3000 (Corbett Life Science, Australia). A typical qRTPCR run was as follows: 1 min at $95{ }^{\circ} \mathrm{C}, 40$ cycles of 10 sec at $95{ }^{\circ} \mathrm{C}, 15 \mathrm{sec}$ at $55{ }^{\circ} \mathrm{C}$ and $20 \mathrm{sec}$ at $72{ }^{\circ} \mathrm{C}$ [67]. Transcriptional differences were calculated using the $\Delta \Delta \mathrm{C}_{\mathrm{T}}$ method [68]. The 16S rRNA (A1S_r01) and gapDH (A1S_2501) transcription levels were used as a reference.

\section{Additional files}

Additional file 1: Position of the Tn10:kan:gfp insertion within the
A. baumannii 17978hm non-pellicle forming mutants.
Additional file 2: Oligonucleotides used for cloning, sequencing
and qRT-PCR.
Additional file 3: Growth curve of the transposon insertion
mutants. A. baumannii insertion mutants were subcultured 1:100 dilution
into fresh Luria-Bertani broth; $200 \mu \mathrm{L}$ samples were taken every hour and
the $\mathrm{OD}_{600}$ determined spectroscopically.

\section{Competing interests}

The authors declare that they have no competing interests.

\section{Authors' contributions}

SKG, BAE, UHS and MHB designed the research project. SKG, BAE and UHS carried out the experiments and SKG, BAE, UHS and MHB wrote the manuscript. All authors have read and approved the final manuscript.

\section{Acknowledgements}

This project was financially supported by the National Health and Medical Research Council Australia Project Grant 535053 and a Flinders Medical Research Foundation Grant. SKG is the recipient of a Flinders University Research Scholarship (FURS).

\section{Author details}

'School of Biological Sciences, Flinders University, GPO Box 21005001 Adelaide, SA, Australia. ${ }^{2}$ Research Centre for Infectious Diseases, School of Biological Sciences University of Adelaide, Adelaide, Australia.

Received: 15 January 2015 Accepted: 11 May 2015

Published online: 06 June 2015

\section{References}

1. Bergogne-Bérézin E. Treatment of Acinetobacter infections. Expert Opin Investig Drugs. 1997;6(2):119-27.

2. McQueary CN, Actis LA. Acinetobacter baumannii biofilms: Variations among strains and correlations with other cell properties. J Microbiol. 2011;49(2):243-50

3. Dijkshoorn L, Nemec A, Seifert H. An increasing threat in hospitals: multidrug-resistant Acinetobacter baumannii. Nat Rev Microbiol. 2007;5(12):939-51

4. Shin JA, Chang YS, Kim HJ, Kim SK, Chang J, Ahn CM, et al. Clinical outcomes of tigecycline in the treatment of multidrug-resistant Acinetobacter baumannil infection. Yonsei Med J. 2012;53(5):974-84.

5. Roca I, Espinal P, Vila-Farrés X, Vila J. The Acinetobacter baumannii oxymoron: commensal hospital dweller turned pan-drug-resistant menace. Front Microbiol. 2012;23(3):148
6. Peleg AY, Seifert H, Paterson DL. Acinetobacter baumannii: emergence of a successful pathogen. J Clin Microbiol Rev. 2008;21(3):538-82.

7. Ramirez MS, Don M, Merkier AK, Bistué AJ, Zorreguieta A, Centrón D, et al. Naturally competent Acinetobacter baumannii clinical isolate as a convenient model for genetic studies. J Clin Microbiol. 2010;48(4):1488-90.

8. Neely AN, Maley MP, Warden GD. Computer keyboards as reservoirs for Acinetobacter baumannii in a burn hospital. Clin Infect Dis. 1999:29(5):1358-60.

9. Donlan RM, Costerton JW. Biofilms: survival mechanisms of clinically relevant microorganisms. Clin Microbiol Rev. 2002;15(2):167-93.

10. Karaiskos I, Galani L, Baziaka F, Giamarellou H. Intraventricular and intrathecal colistin as the last therapeutic resort for the treatment of multidrug-resistant and extensively drug-resistant Acinetobacter baumannii ventriculitis and meningitis: a literature review. Int J Antimicrob Agents. 2013;41(6):499-508.

11. Strassle P, Thom KA, Johnsonm JK, Leekha S, Lissauer M, Zhu J, et al. The effect of terminal cleaning on environmental contamination rates of multidrugresistant Acinetobacter baumannii. Am J Infect Control. 2012;40(10):1005-7.

12. Karageorgopoulos DE, Falagas ME. Current control and treatment of multidrug-resistant Acinetobacter baumannii infections. Lancet Infect Dis. 2008:8(12):751-62.

13. Longo F, Vuotto C, Donelli G. Biofilm formation in Acinetobacter baumannii. New Microbiol. 2014:37(2):119-27.

14. Yamamoto $K$, Arai H, Ishii M, Igarashi Y. Involvement of flagella-driven motility and pili in Pseudomonas aeruginosa colonization at the air-liquid interface. Microbes Environ. 2012;27(3):320-3.

15. Moonmangmee S, Kawabata K, Tanaka S, Toyama H, Adachi O, Matsushita K. A novel polysaccharide involved in the pellicle formation of Acetobacter aceti. J Biosci Bioeng. 2002;93(2):192-200.

16. Yuan J, Chen Y, Zhou G, Chen H, Gao H. Investigation of roles of divalent cations in Shewanella oneidensis pellicle formation reveals unique impacts of insoluble iron. Biochim Biophys Acta. 2013;1830(11):5248-57.

17. Espinal $P$, Martí S, Vila J. Effect of biofilm formation on the survival of Acinetobacter baumannii on dry surfaces. J Hosp Infect. 2012;80(1):56-60.

18. Kanchanarach W, Theeragool G, Inoue T, Yakushi T, Adachi O, Matsushita K. Acetic acid fermentation of Acetobacter pasteurianus: relationship between acetic acid resistance and pellicle polysaccharide formation. J Biosci Bioeng. 2010:74(8):1591-7.

19. Sambandan D, Dao DN, Weinrick BC, Vilchéze C, Gurcha SS, Ojha A, et al. Keto-mycolic acid-dependent pellicle formation confers tolerance to drug-sensitive Mycobacterium tuberculosis. MBio. 2013;4(3):e00222-00213.

20. Tomaras AP, Dorsey CW, Edelmann RE, Actis LA. Attachment to and biofilm formation on abiotic surfaces by Acinetobacter baumannii: involvement of a novel chaperone-usher pili assembly system. Microbiol. 2003;149(12):3473-84.

21. Kobayashi K. Bacillus subtilis pellicle formation proceeds through genetically defined morphological changes. J Bacteriol. 2007;189(13):4920-31.

22. Martí S, Nait Chabane Y, Alexandre S, Coquet L, Vila J, Jouenne T, et al. Growth of Acinetobacter baumannii in pellicle enhanced the expression of potential virulence factors. PLoS One. 2011;6(10):e26030.

23. Nait Chabane Y, Martí S, Rihouey C, Alexandre S, Hardouin J, Lesouhaitier O, et al. Characterisation of pellicles formed by Acinetobacter baumannii at the air-liquid interface. PLoS One. 2014;9(10):e111660.

24. Lazar V. Quorum sensing in biofilms - How to destroy the bacterial citadels or their cohesion/power? Anaerobe. 2011;17(6):280-5.

25. de Kievit TR. Quorum sensing in Pseudomonas aeruginosa biofilms. Environ Microbiol. 2009;11(2):279-88.

26. Kalivoda EJ, Brothers KM, Stella NA, Schmitt MJ, Shanks RM. Bacterial cyclic AMP-phosphodiesterase activity coordinates biofilm formation. PLoS One. 2013:8(7):e71267.

27. Shemarova IV. CAMP-dependent signal pathways in unicellular eukaryotes. Crit Rev Microbiol. 2009:35(1):23-42

28. Skorupski K, Taylor RK. Cyclic AMP and its receptor protein negatively regulate the coordinate expression of cholera toxin and toxin-coregulated pilus in Vibrio cholerae. Proc Natl Acad Sci U S A. 1997;94(1):265-70.

29. Ono K, Oka R, Toyofuku M, Sakaguchi A, Hamada M, Yoshida S, et al. CAMP signaling affects irreversible attachment during biofilm formation by Pseudomonas aeruginosa PAO1. Microbes Environ. 2014;29(1):104-6.

30. Wolfgang MC, Lee VT, Gilmore ME, Lory S. Coordinate regulation of bacteria virulence genes by a novel adenylate cyclase-dependent signaling pathway. Dev Cell. 2003;4(2):253-63.

31. Yahr TL, Vallis AJ, Hancock MK, Barbieri JT, Frank DW. ExoY, an adenylate cyclase secreted by the Pseudomonas aeruginosa type III system. Proc Natl Acad Sci U S A. 1998;95(23):13899-904. 
32. Jimenez PN, Koch G, Thompson JA, Xavier KB, Cool RH, Quax WJ. The multiple signaling systems regulating virulence in Pseudomonas aeruginosa Microbiol Mol Biol Rev. 2012;76(1):46-65

33. Fuchs EL, Brutinel ED, Jones AK, Fulcher NB, Urbanowski ML, Yahr TL, et al. The Pseudomonas aeruginosa Vfr regulator controls global virulence factor expression through cyclic AMP-dependent and -independent mechanisms J Bacteriol. 2010;192(14):3553-64.

34. Eijkelkamp BA, Stroeher UH, Hassan KA, Papadimitrious MS, Paulsen IT, Brown MH. Adherence and motility characteristics of clinical Acinetobacter baumannii isolates. FEMS Microbiol Lett. 2011;323(1):44-51.

35. Martí S, Rodríguez-Bano J, Catel-Ferreira M, Jouenne T, Vila J, Seifert H, et al. Biofilm formation at the solid-liquid and air-liquid interfaces by Acinetobacter species. BMC Res Notes. 2011;4(5):1-4.

36. Pour NK, Dusane DH, Dhakephalkar PK, Zamin FR, Zinjarde SS, Chopade BA Biofilm formation by Acinetobacter baumannii strains isolated from urinary tract infection and urinary catheters. FEMS Immunol Med Microbiol. 2011:62(3):328-38.

37. Costa GF, Tognim MC, Cardoso CL, Carrara-Marrone FE, Garcia LB. Preliminary evaluation of adherence on abiotic and cellular surfaces of Acinetobacter baumannii strains isolated from catheter tips. Braz J Infect Dis. 2006;10(5):346-51.

38. Furuhata K, Kato Y, Goto K, Hara M, Fukuyama M. Diversity of heterotrophic bacteria isolated from biofilm samples and cell surface hydrophobicity. J Gen Appl Microbiol. 2009;55(1):69-74.

39. Kouidhi B, Zmantar T, Hentati H, Bakhrouf A. Cell surface hydrophobicity, biofilm formation, adhesives properties and molecular detection of adhesins genes in Staphylococcus aureus associated to dental caries. Microb Pathog. 2010;49(1-2):14-22

40. Chiku K, Tsunemi K, Yamamoto M, Ohnishi-Kameyama M, Yoshida M, Ishii T, et al. Defects in D-rhamnosyl residue biosynthetic genes affect lipopolysaccharide structure, motility, and cell-surface hydrophobicity in Pseudomonas syringae pathovar glycinea race 4. Biosci Biotechnol Biochem. 2013;77(3):505-10.

41. Raut J, Rathod V, Karuppayil SM. Cell surface hydrophobicity and adhesion: a study on fifty clinical isolates of Candida albicans. Nippon Ishinkin Gakkai Zasshi. 2010;51(3):131-6.

42. Delcour AH. Outer membrane permeability and antibiotic resistance. Biochim Biophys Acta. 2009:1794(5):808-16.

43. Eijkelkamp BA, Stroeher UH, Hassan KA, Elbourne LD, Paulsen IT, Brown MH. $\mathrm{H}-\mathrm{NS}$ plays a role in expression of Acinetobacter baumannii virulence features. Infect Immun. 2013;81(7):2574-83.

44. Stretton S, Techkarnjanaruk S, McLennan AM, Goodman AE. Use of green fluorescent protein to tag and investigate gene expression in marine bacteria. Appl Environ Microbiol. 1998;64(7):2554-9.

45. Fuchs EL, Brutinel ED, Klem ER, Fehr AR, Yahr TL, Wolfgang MC. In vitro and in vivo characterization of the Pseudomonas aeruginosa cyclic AMP (CAMP) phosphodiesterase CpdA, required for CAMP homeostasis and virulence factor regulation. J Bacteriol. 2010;192(11):2779-90.

46. Hunger M, Schmucker R, Kishan V, Hillen W. Analysis and nucleotide sequence of an origin of DNA replication in Acinetobacter calcoaceticus and its use for Escherichia coli shuttle plasmids. Gene. 1990;87(1):45-51.

47. Clemmer KM, Bonomo RA, Rather PN. Genetic analysis of surface motility in Acinetobacter baumannii. Microbiol. 2011;157(9):2534-44.

48. Stewart CR, Rossier O, Cianciotto NP. Surface translocation by Legionella pneumophila: a form of sliding motility that is dependent upon type ॥ protein secretion. J Bacteriol. 2009;191(5):1537-46.

49. Rumbo-Feal S, Gómez MJ, Gayoso C, Álvarez-Fraga L, Cabral MP, Aransay $\mathrm{AM}$, et al. Whole transcriptome analysis of Acinetobacter baumannii assessed by RNA-sequencing reveals different mRNA expression profiles in biofilm compared to planktonic cells. PLoS One. 2013;8(8):e72968.

50. Henrichsen J. The influence of changes in the environment on twitching motility. Acta Pathol Microbiol Scand B. 1975;83(3):179-86.

51. Skiebe E, de Berardinis V, Morczinek P, Kerrinnes T, Faber F, Lepka D, et al. Surface-associated motility, a common trait of clinical isolates of Acinetobacter baumannii, depends on 1,3-diaminopropane. Int J Med Microbiol. 2012;302(3):117-28

52. McDonough KA, Rodriguez A. The myriad roles of cyclic AMP in microbial pathogens: from signal to sword. Nat Rev Microbiol. 2012;10(1):27-38.

53. Saroj SD, Rather PN. Streptomycin inhibits quorum sensing in Acinetobacter baumannii. Antimicrob Agents Chemother. 2013;57(4):1926-9.
54. Carruthers MD, Harding CM, Baker BD, Bonomo RA, Hujer KM, Rather PN, et al. Draft genome sequence of the clinical isolate Acinetobacter nosocomialis strain M2. Genome Announc. 2013;1(6):e00906-13.

55. Vallet I, Olson JW, Lory S, Lazdunski A, Filloux A. The chaperone/usher pathways of Pseudomonas aeruginosa: identification of fimbrial gene clusters (cup) and their involvement in biofilm formation. Proc Natl Acad Sci U S A. 2001;98(12):6911-6.

56. Eijkelkamp BA, Stroeher UH, Hassan KA, Paulsen IT, Brown MH. Comparative analysis of surface-exposed virulence factors of Acinetobacter baumannii. BMC Genomics. 2014;15:1020

57. Choi AH, Slamti L, Avci FY, Pier GB, Maira-Litrán T. The pgaABCD locus of Acinetobacter baumannii encodes the production of poly-b-1-6-Nacetylglucosamine, which is critical for biofilm formation. J Bacteriol. 2009;191(19):5953-63.

58. Wada A, Mikkola R, Kurland CG, Ishihama A. Growth phase-coupled changes of the ribosome profile in natural isolates and laboratory strains of Escherichia coli. J Bacteriol. 2000;182(10):2893-9.

59. Eijkelkamp BA, Hassan KA, Paulsen IT, Brown MH. Investigation of the human pathogen Acinetobacter baumannii under iron limiting conditions. BMC Genomics. 2011;12(1):126.

60. Hanahan D. Studies on transformation of Escherichia coli with plasmids. J Mol Biol. 1983;166(4):557-80.

61. Simon R, Priefer U, Puhler A. A broad host range mobilization system for invivo genetic-engineering - transposon mutagenesis in Gram-negative bacteria. BioTechnol. 1983;1(9):784-91.

62. Yanisch-Perron C, Vieira J, Messing J. Improved M13 phage cloning vectors and host strains: nucleotide sequences of the M13mp18 and pUC19 vectors. Gene. 1985;33(1):103-19.

63. Mussi MA, Gaddy JA, Cabruja M, Arivett BA, Viale AM, Rasia R, et al. The opportunistic human pathogen Acinetobacter baumannii senses and responds to light. J Bacteriol. 2010;192(24):6336-45.

64. Golic A, Vaneechoutte M, Nemec A, Viale AM, Actis LA, Mussi MA. Staring at the cold sun: blue light regulation is distributed within the genus Acinetobacter. PLoS One. 2013;8(1):e55059.

65. Rosenberg E, Gottlieb A, Rosenberg M. Inhibition of bacterial adherence to hydrocarbons and epithelial cells by emulsan. Infect Immun. 1983;39(3):1024-8.

66. Matthysse AG, Stretton S, Dandie C, McClure NC, Goodman AE. Construction of GFP vectors for use in gram-negative bacteria other than Escherichia coli. FEMS Microbiol Lett. 1996;145(1):87-94.

67. Brazma A, Vilo J. Gene expression data analysis. Microbes Infect. 2001;3(10):823-9.

68. Livak KJ, Schmittgen TD. Analysis of relative gene expression data using real-time quantitative PCR and the 2(-Delta Delta C(T)) method. Methods. 2001;25(4):402-8.

\section{Submit your next manuscript to BioMed Central and take full advantage of:}

- Convenient online submission

- Thorough peer review

- No space constraints or color figure charges

- Immediate publication on acceptance

- Inclusion in PubMed, CAS, Scopus and Google Scholar

- Research which is freely available for redistribution 